\title{
Marker-Assisted Backcrossing For Introgression of Broad-Spectrum Bacterial Leaf Blight Resistance In MR297 Malaysian Elite Variety
}

\section{Saba Jasim Aljumaili}

Universiti Putra Malaysia (UPM) https://orcid.org/0000-0002-8524-0534

M. Y. Rafii (D mrafi@upm.edu.my )

Universiti Putra Malaysia (UPM)

\section{S. S. Zaharah}

Universiti Putra Malaysia (UPM)

\section{A. Khairulmazmi}

Universiti Putra Malaysia (UPM)

Oladosu Yusuff

Universiti Putra Malaysia (UPM)

\section{Research Article}

Keywords: Oryza sativa L, Xanthomonas oryzae, backcrossing, microsatellites, foreground selection, background selection, recurrent parent genome recovery

Posted Date: February 8th, 2022

DOI: https://doi.org/10.21203/rs.3.rs-751084/v1

License: (c) (i) This work is licensed under a Creative Commons Attribution 4.0 International License. Read Full License 


\title{
Marker-Assisted Backcrossing For Introgression of Broad-Spectrum Bacterial Leaf Blight Resistance in MR297 Malaysian Elite Variety
}

\author{
Saba Jasim Aljumaili ${ }^{1}$, M. Y. Rafii ${ }^{1,2}$, S. S. Zaharah ${ }^{2}$, A. Khairulmazmi ${ }^{2}$, and Oladosu Yusuff ${ }^{1}$ \\ ${ }^{1}$ Laboratory of Climate-Smart Food Crop Production, Institute of Tropical Agriculture and Food Security, \\ Universiti Putra Malaysia (UPM), 43400 Serdang, Selangor, Malaysia \\ ${ }^{2}$ Department of Crop Science, Faculty of Agriculture, Universiti Putra Malaysia (UPM), 43400 Serdang, Selangor, \\ Malaysia
}

Correspondence should be addressed to: M. Y. Rafi; mrafi@upm.edu.my

\begin{abstract}
One of the most critical aspects of marker-assisted backcross breeding is recurrent parent genome recovery (RPGR). RPGR ensures that only the genes of interest are retained without further segregation in the recombined progenies while the unwanted genomic segments are completely deleted. This experiment aimed to introgress multiple bacterial leaf blight (BLB) resistance genes against using marker-assisted backcross breeding. Four Xoo resistance genes viz: Xa21, xa13, xa5, and Xa4 from IRBB60 were introgressed into the genetic background of MR297 Malaysian, which is considered a high yield. Polymorphic functional linked markers to target genes and SSR markers were used for both foreground and background selection. The percentage of RPGR in the selected lines, a background selection was adopted using 83 approved polymorphic microsatellites markers. The study results reveal RPGR of $81.94 \%, 92.30 \%$, and $95.32 \%$ at $\mathrm{BC} 1 \mathrm{~F} 1, \mathrm{BC} 2 \mathrm{~F} 1$, and $\mathrm{BC} 2 \mathrm{~F} 2$, respectively. Marker-assisted backcross breeding often shows a faster introgression resistance gene than traditional breeding. The introgression of four BLB resistance genes Xa21, xa13, $\mathrm{xa} 5$, and $\mathrm{Xa} 4$ in the nine newly developed lines would provide durable and broad-spectrum resistance against the bacterial leaf blight. The newly created lines were suggested for commercial production as new rice varieties.
\end{abstract}

Keywords: Oryza sativa L., Xanthomonas oryzae; backcrossing; microsatellites; foreground selection; background selection; recurrent parent genome recovery 


\section{Introduction}

2 Rice is one of the major cereal crops that play a crucial role in human diets. Asia is the highest producer and consumer 3 of rice, with over 150 million ha of arable land dedicated to rice production. Rice crops can grow rapidly and produce 4 high yields, provided a favorable environmental situation. The crop requires limited application of fertilizer. It does 5 well with a sufficiently large quantity of micronutrients in saline water. Many factors could lead to higher production of rice in various agricultural areas. These include availability and further expansion of irrigation facilities, the provision of subsidies for machinery, fertilizers, seeds, irrigation, and new technologies. The human population has

8 been increasing at an alarming rate (Jasim Aljumaili et al., 2018). Assert that the world population would increase to more than 8 billion and 9 billion by 2030 and 2050, respectively. Thus, to prevent hunger, population growth will require a 40 percent increase in rice production. However, the production of rice is affected by many diseases. For instance, Blight is one of the most devastating bacterial infectious diseases in rice production in various parts of the world. These diseases bring about a significant setback in rice production in the world.

One from significant pathogens Xanthomonas oryzae pv oryzae (Xoo), that cause bacterial leaf blight. Due to prevent the disease from spreading, viable yield production and resistance to biotic stress affected by Blight (BLB) are required (Singh, Sarma, Singh, \& Nandan, 2013). Rice productivity has improved significantly as a result of substantial progress in developing successful varieties that can withstand various types of biotic and abiotic stress. These were obtained as a result of traditional breeding long-term success. The advent of new biotypes necessitated the pyramiding for different resistance genes to varieties of perfect agronomic value enduring resistance. That allows the cultivars to survive pathogen attacks and grow in disadvantageous environmental factors. Backcrossing considers the typical way to introducing into an elite variety a single gene regulating a specific characteristic that includes two parents, one as a donor and the other as a recipient. When the receiver parent is used repeatedly in the crossing scheme, it is referred to as the recurrent parent. It has been possible to transfer gene which resistance a disease from one variety (typically not superior) to another variety, which is a selected type. For instance, the recurrent "parent's" essential characteristics, such as a high-yielding trait, can be retained accurately and efficiently through marker-assisted backcross breeding. This method integrates the identified locus of the recurrent parent, the particular gene of attention acquired from the donor.

It also decreases the donor parent genome, thus reducing linkage drag and assisting in recovering the recurrent parent genome. Functional molecular markers, like simple sequence repeats (SSR/microsatellite) markers, may also be used (Das, Rao, Varier, Prakash, \& Prasad, 2018). Therefore, the marker technique helps the backcross breeding without losing its genetic background in integrating disease resistance in rice. This could also be achieved through multiple backcrossing to the recurrent parent. The marker-assisted selection of background also made it possible to recover the recurrent parent genome. However, the marker-assisted background selection has some drawbacks, including the expensive molecular markers and the limits of SSR in identifying polymorphisms and the essential to the quick performance of the entire procedure. Other factors such as labor-intensive and time-consuming limitations on natural screening of BLB because of variations in the grade of usual infection affect the process (Yugander et al., 2018). 
Artificial BLB inoculation may be the most efficient screening process. Other methods, for instance, pricking leaves are inoculated, spraying bacterial suspension on the plants, clipping the leaves, and sprinkle by bacterial suspension,

3 as well as submersion the seedlings in bacterial suspension before transplanting, both useful. In the marker-assisted

4 backcrossing, a marker used to select the target locus, as a result, improves the recovery of the recurring parent

5 genome. Three levels have been identified in the marker-assisted backcross breeding process: foreground selection,

6 background selection, and recombinant selection (Collard \& Mackill, 2008). Further, the background selection is used

7 to speed up the ratio of the recurrent parent genome recovery (RPGR) and save some breeder selection cycles (Hasan

8 et al., 2015). At each point of the backcrossing process, the ratio of the donor parent genome is reduced in nearly semi.

9 As a result, the donor parent genome recovery percentage is represented as a percentage of the RPGR proportion

10 (Matthew, 2012). Additionally, marker alleles for a recurrent parent might be used to identify all genomic regions

11 during background selection, and phenotypic screening may be used to pick the target locus. The recurrent parent

12 genome recovery during marker-assisted backcross breeding is facilitated using the background selection.

13 Backcrossing leads to varietal progression and complete line conversion, whereas more backcrossing leads to varietal

14 progression and complete line transformation (Hospital, 2001; Mackill, 2006). As a result, the current research aims

15 to compute functional and SSR markers to retrieve the parent genome of novel introgression lines after the cross 16 MR297 with IRBB60.

\section{Materials and Methods}

\section{Germplasm Source and Breeding Procedure}

A cross between MR297 and IRBB60 was used to develop an F1 hybrid. As for IRBB60, it is an IRRI assortment through four Xoo R-genes: Xa21, xa13, xa5, and Xa4 (Singh et al., 2013). In contrast, MR297 has a high yield. MR297 served as the female/recipient as well as the recurrent parent through backcrossing and hybridization, while IRBB60 only used as the male parent (donor) in hybridization, resulting in the creation of F1 plants. To confirm heterozygous F1 plants, a foreground set of SSR and functional markers were applied. In all backcross generations, MR297 was used as a recurrent parent to restore its high-yielding characteristic. The foreground markers that contained both SSR and functional markers were utilized for the foreground selection of target genes of interest at every stage of the backcrossing process. An overall of 83 polymorphic SSR markers was applied to background selection. Progenies with a strong recurrent parent genome recovery and a small donor parent genome section were chosen for the breeding program. To recombine the genes, $\mathrm{BC} 2 \mathrm{~F} 2$ plants were selfed. The MABB breeding structure approved in the study is shown in Figure 1. 


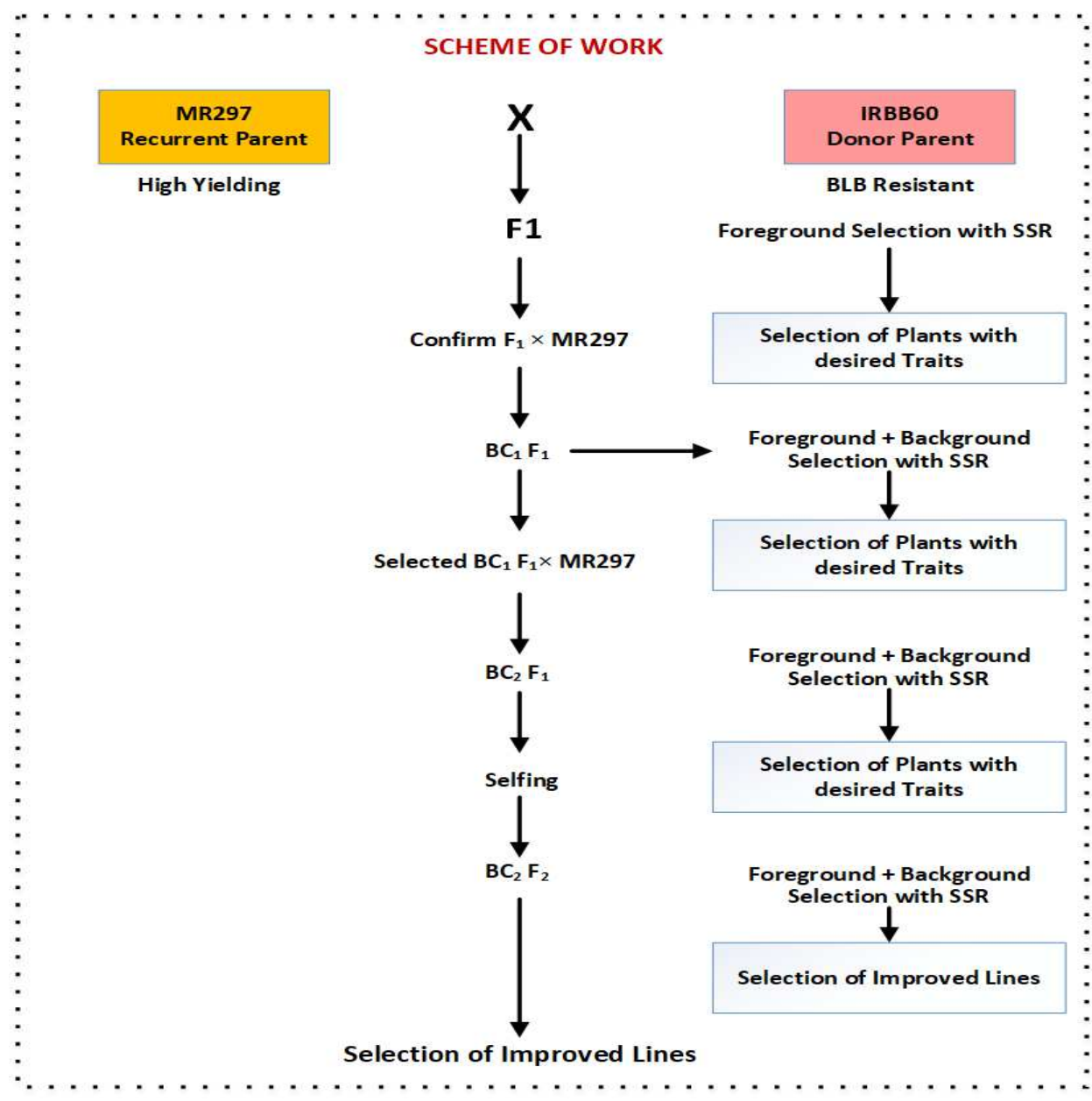

Figure 1. Marker assisted backcross breeding program for blight resistance.

\section{DNA Extraction and Screening for Molecular Markers}

6 Extracted from developing plants, fresh young leaves $(0.5 \mathrm{~g})$ after two weeks of transplanting in the glasshouse were used for genomic DNA extraction. Doyle and Doyle proposed a method of CTAB DNA extraction (Doyle, 1990; Jasim Aljumaili et al., 2018) and was improved by another researcher in (Ashkani et al., 2012), which was approved in this research. Nanodrop spectrophotometry system (Product specification: ND1000 Spectrophotometer USA) was used to determine DNA concentration, accuracy, and purity. The A260/280 proportion characterizes the amount of protein contamination in DNA, whereas the A260/230 ratio characterizes the scale of organic pollutants in nucleic acid. The generally accepted ratio of pure' DNA is $\sim 1.8$ 260/280, whereas A260/230 from 2.0 to 2.2 is usually passable

13 as 'pure' DNA at $230 \mathrm{~nm}$ absorbance. Nevertheless, DNA samples nominated with A260/280 purity extent from 1.8 14 to 2.0 are considered the best appropriate samples for DNA nominated for polymerase chain reaction (PCR). Gel electrophoresis was used to confirm the presence of DNA in the extracted sample. 
1 A singular high-molecular-weight DNA band Image doc result displayed on a computer screen was considered decent

2 DNA, whereas messy or multiple allelic DNA bands were deemed to be of low quality and unsuitable for PCR. The

3 polymorphism of foreground and background markers associated with resistance to bacterial leaf blight was first

4 screened for, and appropriate ones were chosen. (Table 1). A combination of 7.5 uL DNA master mix $+4.5 \mathrm{uL}$ of

5 nuclease-free water $+1 \mathrm{uL}$ of DNA $+1 \mathrm{uL}$ of reverse primer $+1 \mathrm{uL}$ of forwarding primer sample was prepared and

6 turned for by mixing utilizing a small revolving unit for $15 \mathrm{~s}$. The PCR machine was run for $3.5 \mathrm{~h}$ (Jasim Aljumaili et

7 al., 2018).

8

Table 1. SSR markers used for background selection.

\begin{tabular}{cl}
$\begin{array}{c}\text { Chro. No. } \\
\text { Position }\end{array}$ & \multicolumn{1}{c}{ Name of Polymorphic SSR Markers Identified } \\
\hline 1 & RM431, RM272, RM302, RM10025 \\
\hline 2 & RM262, RM525, RM573, RM452, RM250, RM5390, RM561, RM211, RM3248, RM154 \\
\hline 3 & RM7, RM218, RM520, , RM6308, RM232, RM130 \\
\hline 4 & MP, RM518, RM8213, RM241, RM127, RM3843, RM261 \\
\hline 5 & RM13, RM1089, RM1237, RM305, RM233A, RM1253, RM122, RM153,RM169 \\
\hline 6 & RM588, RM508, RM6836, RM8225, RM402,RM276 \\
\hline 7 & RM72, RM336, RM1134, RM10, RM432, RM1973 \\
\hline 8 & RM547, RM447, RM6208, RM25, RM310, RM544, RM3, RM5556, RM3761, Xa13prom \\
\hline 9 & RM23865, RM410, RM342, OSR28, RM219, RM160 \\
\hline 10 & RM1375, RM294A, RM333, RM375 \\
\hline 11 & PTA248, RM6293, RM206, RM21, RM206, Xa21FR \\
\hline 12 & RM313, RM309, RM463, RM7376, RM117, RM28076, RM1261, RM415, RM12 \\
\hline
\end{tabular}

The progenies were scored specifically from the banding patterns obtained in the Gel Imager® (GelDocTM XR, Bioparent's banding pattern in the banding pattern and were scored as 'A' to indicate genotypic the homozygous donor parent's banding of MR297 variety. While progenies that followed the pattern were scored as 'B' to indicate a genotypic resemblance of IRBB60 variety. On the contrary, 'H' was assigned to progenies that adopted heterozygous banding trends, indicating both parents' genotypic similarity. 
Choosing a Foreground and Background

2 Six of the 15 linked markers tested for bacterial leaf blight resistance genes were confirmed to be polymorphic between 3 the two parents. Only progenies with Xoo resistance genes were chosen using the foreground markers. Overall of 475

4 SSR markers were molecularly screened for heterogeneous alleles across rice's 12 chromosomes (polymorphism). The

583 polymorphic rice markers were identified from the 475 SSR markers screened and used for background selection

6 (Table1). They were uniformly distributed around the 12 chromosomes, with at least four polymorphic markers on 7 each.

Phenotyping, Agro-Morphological Trait Characterization, and Data Analysis

10 To carry out the phenotypic selection, the entire population was exposed to it after the foreground and background 11 selections were completed at each stage of backcrossing. Only plants with the direct visual phenotypic expression of 12 the Xoo resistance genes were selected for phenotypic selection. Suitable plants' agro-morphological characteristics 13 for yield and yield component traits were recorded using the standard procedure defined by IRRI (Rice, 1996; Zuki et 14 al., 2020). The data was analyzed using a chi-square test on SAS software version 9.4 compared to Mendelian genetics 15 after the foreground marker genotyping. Also, descriptive statistical analysis using the same software on quantitative 16 data collected from yield and yield components. In order to calculate the maximal RPGR, the genotypic data obtained 17 from background selection with the 83 polymorphic markers were additionally analyzed using a genetic program named Graphical Genotyper (GGT 2.0).

\section{Results}

\section{In the foreground, there are F1 hybrids and backcross populations}

22 From 43, F1 plants developed, the functional marker Xa21FR with heterozygous alleles revealed 30 actual F1 plants $23 \mathrm{Xa21}$, xa13, xa5, and Xa4 bacterial leaf blight resistance genes were only accepted in five F1 plants, and hybrids were 24 nominated for backcrossing (Figure 2). According to the results, out of 110, just 53 plants grown were reported to 25 gain the Xa21 BLB R-gene at BC1F1. Xa4, xa5, and xa13 BLB R-genes are also present in 57, 50, and 58 plants, 26 sequentially, according to the findings. The goodness of fit resulted from the Chi-square $\left(\chi^{2}\right)$ study, indicating that there is no substantial difference between Mendel's segregation ratio 1:1 (single-gene model) for foreground markers at $\mathrm{BC} 1 \mathrm{~F} 1$ (Table 2). The $\mathrm{BC} 1 \mathrm{~F} 1$ choice was done on the five progenies reported to have all BLB resistance genes tested. 


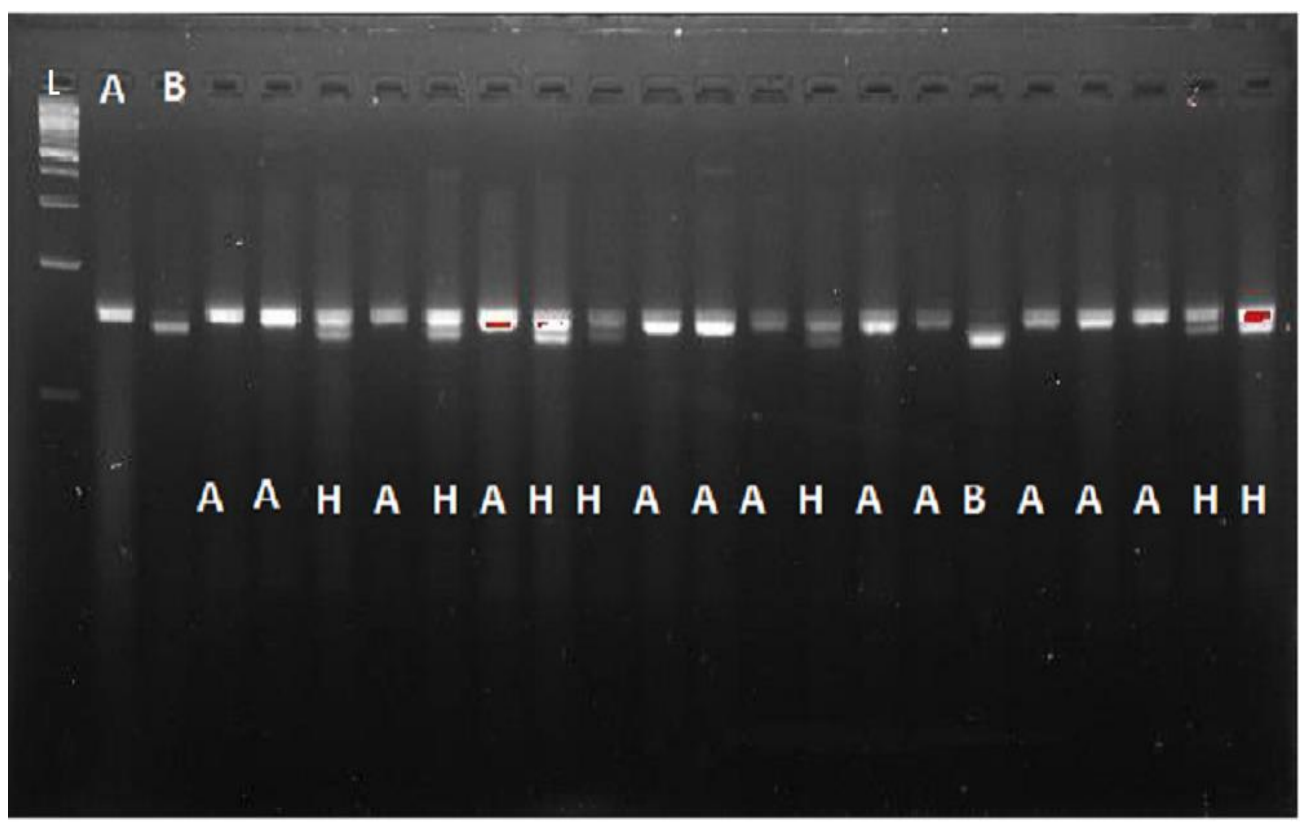

Figure 2. Foreground selection of F1 hybrids using RM21 functional marker showing polymorphism between the two parents MR297 (A) and IRBB60 (B), H represents heterozygotes L: 50bp DNA ladder.

Table 2. Foreground marker segregation analysis of the BC1F1 progenies.

\begin{tabular}{|c|c|c|c|c|}
\hline \multirow{2}{*}{$\begin{array}{c}\text { Molecular Marker } \\
\text { BLB }\end{array}$} & \multirow[t]{2}{*}{ Chro. No. } & \multicolumn{2}{|c|}{ Marker Segregation Analysis } & \multirow[t]{2}{*}{$\chi^{2}(1: 1)$} \\
\hline & & A & $\mathrm{H}$ & \\
\hline Xa21FR & 11 & 57 & 53 & 0.146 \\
\hline Xa13prom & 8 & 52 & 58 & 0.326 \\
\hline RM21 & 5 & 60 & 50 & 0.910 \\
\hline MP & 4 & 53 & 57 & 0.145 \\
\hline
\end{tabular}

8 Backcrossing was performed on the selected plants. At BC2F1, 54 heterozygous plants carrying recessive gene xa13

9 and 51 plants carrying dominant Xa21 genes were identified using the functional markers Xa13prom and Xa21FR, 10 respectively 112 plants grown. Additionally, Xa4 and xa5 were found in 52 and 57 plants sequentially. As a result, 11 the plants for the next stage of the crossing were chosen. The chi-square test showed the goodness of fit to a 1:1 12 Mendel's ratio for a single gene model (Table 3). BC2F1 lines were recovered from the nine recurrent parent genomes.

13 Finally, individuals which were homozygous for the donor (IRBB60) parent allele and had a great RPGR percentage 14 were chosen, indicating goodness of fit to the Mendelian predictable 1:2:1 separation proportion BC2F2 (Table 4). 15 This is contrary to the $\mathrm{BC} 2 \mathrm{~F} 2$ result for Xoo resistance. 
Table 3. Foreground marker segregation analysis of the $\mathrm{BC} 2 \mathrm{~F} 1$ progenies.

\begin{tabular}{|c|c|c|c|c|}
\hline \multirow{2}{*}{$\begin{array}{c}\text { Molecular Marker } \\
\text { BLB }\end{array}$} & \multirow[t]{2}{*}{ Chro. No. } & \multicolumn{2}{|c|}{ Marker Segregation Analysis } & \multirow[t]{2}{*}{$\chi^{2}(1: 1)$} \\
\hline & & A & $\mathrm{H}$ & \\
\hline $\mathrm{Xa} 21 \mathrm{FR}$ & 11 & 61 & 51 & 0.892 \\
\hline Xa13prom & 8 & 58 & 54 & 0.142 \\
\hline RM21 & 5 & 55 & 57 & 0.035 \\
\hline MP & 4 & 60 & 52 & 0.571 \\
\hline
\end{tabular}

2

Table 4. Foreground marker segregation analysis of the $\mathrm{BC} 2 \mathrm{~F} 2$ progenies.

\begin{tabular}{ccccc}
\hline Molecular Marker & Chro. No. & Marker Segregation Analysis & $\chi 2$ (1:2:1) \\
\hline BLB & & A & H & B \\
Xa21FR & 11 & 40 & 30 & 26 \\
Xa13prom & 8 & 40 & 30 & 26 \\
RM21 & 11 & 40 & 30 & 26 \\
MP & 4 & 40 & 30 & 26 \\
\hline d.f. $=2 ; \chi 2(0.05,1)=5.99$ & & & \\
\hline
\end{tabular}

\section{Backcross Populations with Marker-Assisted Background Selection}

Nine plants (BC1F1-4, BC1F1-35, BC1F1-17, BC1F1-26, BC1F1-41, BC1F1-8, BC1F1-22, BC1F1-10, and BC1F111) from the progenies evaluated for RPGR at $\mathrm{BC} 1 \mathrm{~F} 1$ were observed to have a minimum of $80 \%$ and above for RPGR.

9 Thus, these individuals were nominated and choose for BC2F1 crossing (Lau et al., 2017; Olalekan et al., 2019). The BC1F1-4 was observed to be the best progeny in the BC1F1 population with $84.20 \%$ of RPGR, a heterozygous portion

11 of just $10.90 \%$, and a decreased donor genome $4.90 \%$. The nine superlative BC2F1 individuals with a lowest of $92.3 \%$

12 (mean recorded) RPGR were chosen after genotyping and further confirmation by phenotyping, based on the RPGR

13 result from marker-assisted context selection of the $\mathrm{BC} 2 \mathrm{~F} 1$. Those nine better $\mathrm{BC} 2 \mathrm{~F} 1$ which selected as the best 14 parental seeds and self-pollination to generate BC2F2. (Figures 3 and 4) 


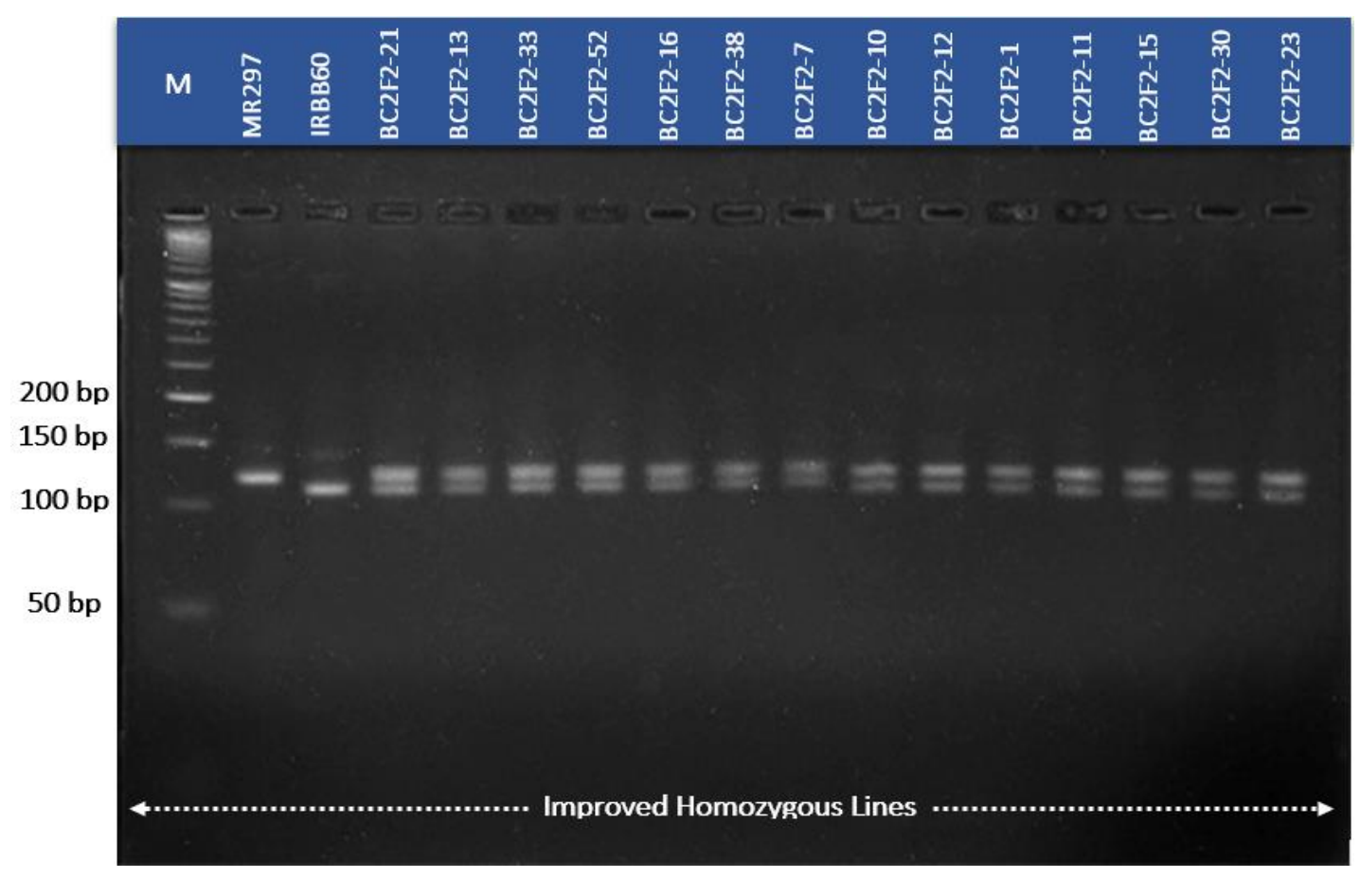

3 Figure 3. Confirmation of bacterial leaf blight resistance in homozygous improved lines using the functional marker 4 Xa21FR.

$200 \mathrm{bp}$

$150 \mathrm{bp}$

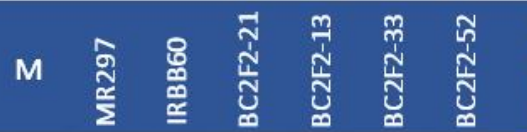

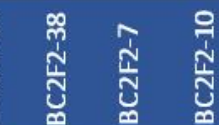

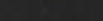

.

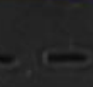

$100 \mathrm{bp}$

50 bp

Figure 4. Confirmation of bacterial leaf blight resistance in homozygous improved lines using the functional marker 
2 The RPGR analysis result shows a range from $92.9 \%$ to $98.8 \%$ at BC2F2 (Figure 5). The highest RPGR was recorded 3 at line BC2F2-21. An average of 95.32\% RPGR was detected to distribute through the 12 chromosomes in the nine 4 selected lines. The genome of the donor parent proportions ranged from 0.5 percent in $\mathrm{BC} 2 \mathrm{~F} 2-21$ to 2.8 percent in $5 \mathrm{BC} 2 \mathrm{~F} 2-12$, with an average of 2.09 percent. Also, the heterozygous genome had a proportion ranging from $0.7 \%$ in $6 \mathrm{BC} 2 \mathrm{~F} 2-21$ to $4.3 \%$ in $\mathrm{BC} 2 \mathrm{~F} 2-12$. After one generation of self-fertilization from $\mathrm{BC} 2 \mathrm{~F} 1$ to $\mathrm{BC} 2 \mathrm{~F} 2$, this finding 7 indicates a $3.02 \%$ growth in recurrent parent genome recovery due to recombination. It also causes a $2.6 \%$ decrease 8 of the donor parent genome and a $0.43 \%$ decrease in the heterozygous genome percentage. The maximum 9 chromosome-wise RPGR of the developed nominated lines detected in the lines BC2F2-21 is displayed in Figure6.

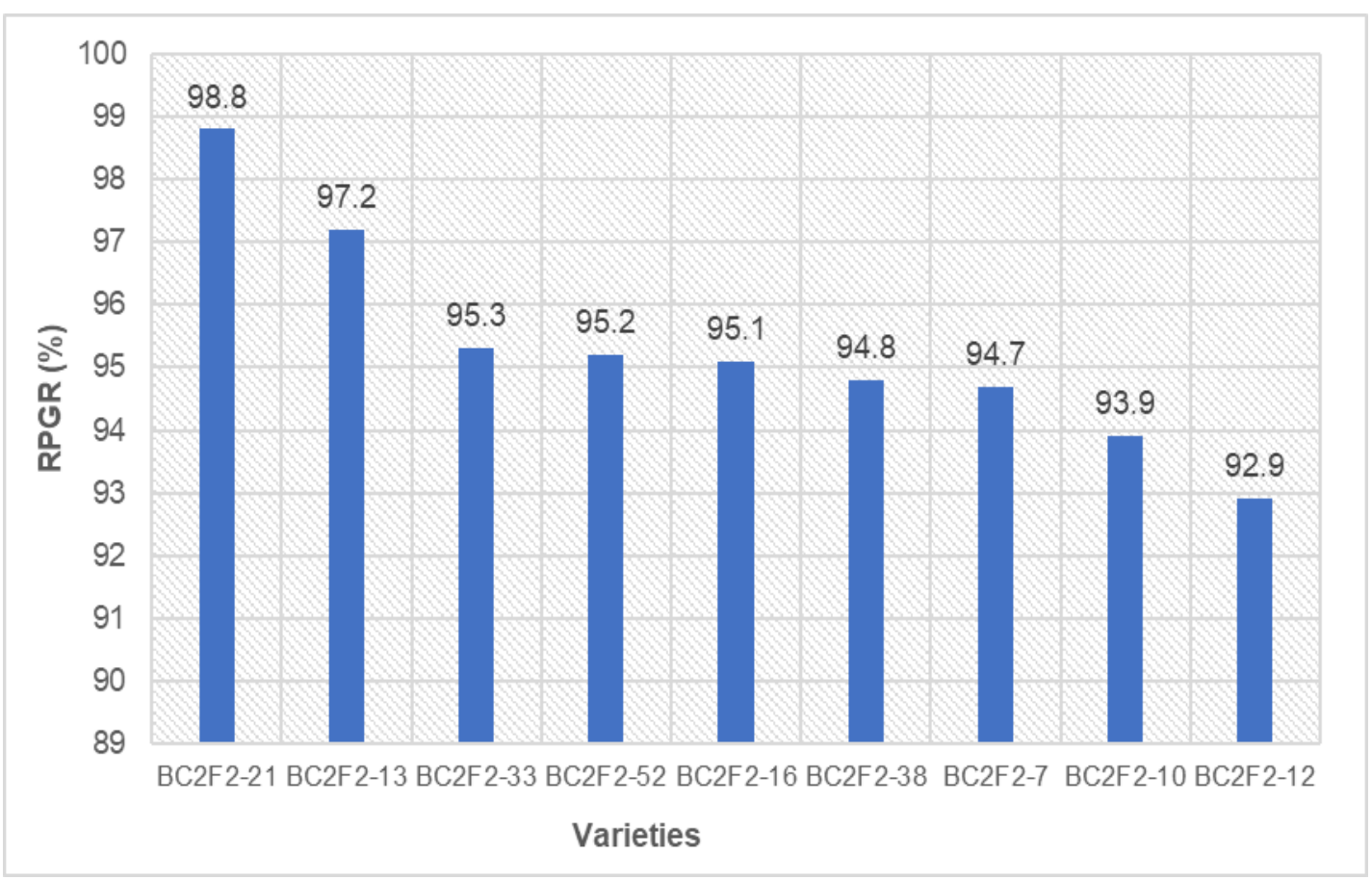

Figure 5. Recurrent parent genome recovery percentage of the improved selected lines. 


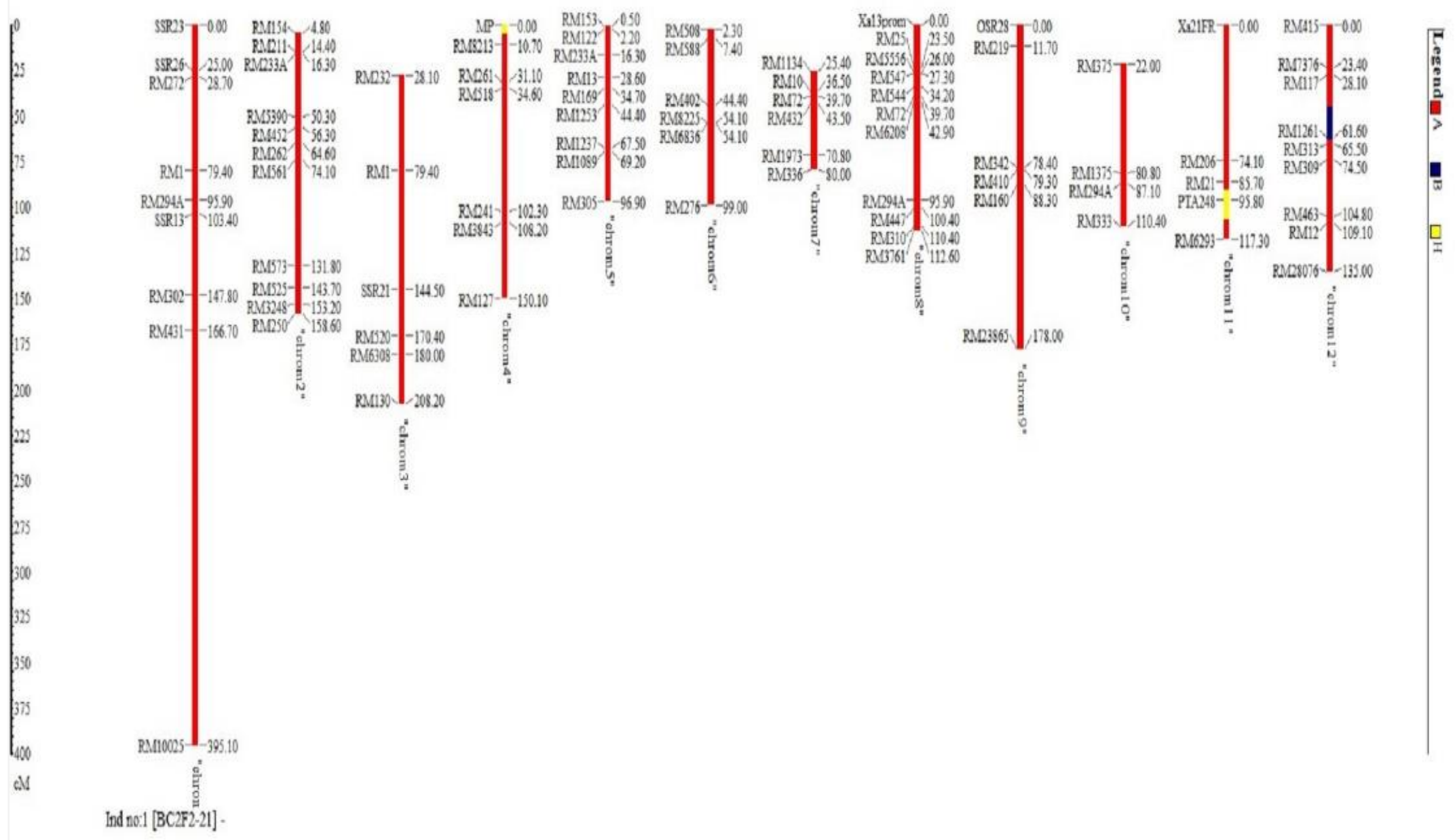


Backcross Generations Show a Genetic Increase in Recurrent Parent Genome Size

2 The size of the recurrent parent genome in BC1F1 was $1202.3 \mathrm{cM}$ to $1259.1 \mathrm{cM}$, whereas it was $13465.2 \mathrm{cM}$ to 1432.5

$3 \mathrm{cM}$ for $\mathrm{BC} 2 \mathrm{~F} 1$ generation. Nonetheless, the recurrent parent genome's mean ranges from $1225.3 \mathrm{cM}$ to $1382.7 \mathrm{cM}$ in

$4 \mathrm{BC} 1 \mathrm{~F} 1$ and $\mathrm{BC} 2 \mathrm{~F} 1$, successively. At the end of the two backcross generations, this shows a $157.4 \mathrm{cM}$ rise. Also, a

5 recurrent parent genome size of $1259.1 \mathrm{~cm}$ was recorded in the individual with the highest RPGR at BC1F1 generation

6 (BC1F1-4). In contrast, the progeny with the maximum RPGR at BC2F1 (BC2F1-20) has a recurrent parent genome

7 size of $1432.5 \mathrm{~cm}$. This designated a genetic rise in the recurrent parent genome size of $173.4 \mathrm{~cm}$. The findings suggest

8 that molecular marker-assisted backcross breeding can restore the recurrent parent genome size in backcross

9 populations over time (Olalekan et al., 2019).

\section{Backcross Generations Show a Genetic Decrease in the Size of the Donor Parent Genome}

The heterozygous segment has genome size ranging from $131.95 \mathrm{cM}(\mathrm{BC} 1 \mathrm{~F} 1-17)$ to $180.9 \mathrm{cM}$ (BC1F1-10) at BC1F1 generation, and from $23.9 \mathrm{cM}(\mathrm{BC} 2 \mathrm{~F} 1-10)$ to $77.7 \mathrm{cM}(\mathrm{BC} 2 \mathrm{~F} 1-32)$ at $\mathrm{BC} 2 \mathrm{~F} 1$ generation. The average size of heterozygous genomes at $\mathrm{BC} 1 \mathrm{~F} 1$ and $\mathrm{BC} 2 \mathrm{~F} 1$ generations are $147.2 \mathrm{cM}$ and $44.8 \mathrm{~cm}$, respectively. Also, the largest heterozygous genome size of $162.9 \mathrm{~cm}$ was recorded in the progeny with the maximum RPGR at BC1F1 generation. On the other hand, a heterozygous genome size of $31.4 \mathrm{~cm}$ was recorded with the individual with the highest RPGR at $\mathrm{BC} 2 \mathrm{~F} 1$. The results reveal a decrease in the size of the heterozygous genome from BC1F1 to BC2F1. Similarly, there decrease in size was observed from the donor genome size when determinate it. At BC1F1 and $\mathrm{BC} 2 \mathrm{~F} 1$, The sizes of the donor parent genomes vary from $73.3 \mathrm{cM}$ to $161.5 \mathrm{cM}$ and $31.4 \mathrm{cM}$ to $91.2 \mathrm{~cm}$, respectively. The average sizes of the donor parent genomes were $122.8 \mathrm{cM}$ and $67.8 \mathrm{cM}$ at $\mathrm{BC} 1 \mathrm{~F} 1$ and $\mathrm{BC} 2 \mathrm{~F} 1$ generations, successively.

The optimum individual at $\mathrm{BC} 1 \mathrm{~F} 1$ measured $73.3 \mathrm{~cm}$, while the optimum progeny at $\mathrm{BC} 2 \mathrm{~F} 1$ measured $31.4 \mathrm{~cm}$. The decline or decrease in donor parent genome size and the heterozygous segment as the study progresses from $\mathrm{BC} 1 \mathrm{~F} 1$ to $\mathrm{BC} 2 \mathrm{~F} 1$ has shown that the substance of backcrossing decreases the donor parent genome whereas the recurrent parent genome is raised or recovered (Hasan et al., 2015).

\section{Selected Backcross Lines' agro-morphological efficiency}

29 Table 5 below presents the results of the agro-morphological features of the developed nominated lines. The mean agronomic features of the nominated lines reported the following results: plant height $(113.41 \mathrm{~cm})$, flag leaf length to width ratio (13.97), number of panicles per hill (16.22), number of days to flowering (77.56), number of days to maturity (105.56), number of effective tillers (16.44), panicle length (32.33), the total number of grains per panicle (172.44), 1000 grain weight (80.80 g), total grain weight per hill (53.87 g), seed length to width ratio (4.22) and yield per hectare $(8.81 \mathrm{t} / \mathrm{ha})$. According to the results, the selected backcross rice lines outperformed their 
Table 5. Comparative agro-morphological performance of the selected improved lines.

\begin{tabular}{|c|c|c|c|c|c|c|c|c|c|c|c|c|c|c|}
\hline $\begin{array}{c}\text { Improved } \\
\text { Lines }\end{array}$ & $\begin{array}{l}\text { PH } \\
(\mathrm{cm})\end{array}$ & FLWR & NP/H & DF & DM & NT & PL (cm) & TNG/P & $\begin{array}{c}\text { 1000GW } \\
(\mathrm{g})\end{array}$ & $\begin{array}{c}\text { TGW/H } \\
\text { (g) }\end{array}$ & SLWR & $\begin{array}{l}\text { Y/HA } \\
\text { (t/ha) }\end{array}$ & \%RPGR & $\mathbf{P}$ \\
\hline $\mathrm{BC} 2 \mathrm{~F} 2-21$ & 109.01 & 12.46 & 14 & 77 & 109 & 12 & 35.56 & 175 & 80.63 & 58.42 & 4.39 & 8.18 & 98.8 & HR \\
\hline $\mathrm{BC} 2 \mathrm{~F} 2-13$ & 116.01 & 14.2 & 13 & 78 & 103 & 14 & 30.96 & 161 & 83.83 & 55.64 & 4.84 & 9.68 & 97.2 & HR \\
\hline $\mathrm{BC} 2 \mathrm{~F} 2-33$ & 112.51 & 15.24 & 14 & 77 & 105 & 18 & 31.06 & 168 & 81.83 & 58.28 & 3.95 & 9.58 & 95.3 & $\mathrm{HR}$ \\
\hline $\mathrm{BC} 2 \mathrm{~F} 2-52$ & 108.21 & 11.74 & 19 & 79 & 104 & 17 & 34.06 & 174 & 78.33 & 57.28 & 4.8 & 9.3 & 95.2 & HR \\
\hline $\mathrm{BC} 2 \mathrm{~F} 2-16$ & 112.71 & 12.06 & 15 & 78 & 106 & 15 & 33.36 & 175 & 82.93 & 61.7 & 3.98 & 9.81 & 95.1 & HR \\
\hline $\mathrm{BC} 2 \mathrm{~F} 2-38$ & 114.21 & 14.49 & 16 & 77 & 107 & 19 & 30.56 & 164 & 82.63 & 47.47 & 3.83 & 8.21 & 94.8 & $\mathrm{HR}$ \\
\hline $\mathrm{BC} 2 \mathrm{~F} 2-7$ & 115.51 & 13.66 & 17 & 79 & 103 & 18 & 29.66 & 158 & 79.63 & 49.12 & 3.92 & 8.22 & 94.7 & $\mathrm{HR}$ \\
\hline $\mathrm{BC} 2 \mathrm{~F} 2-10$ & 117.81 & 16.55 & 20 & 76 & 105 & 20 & 32.16 & 198 & 78.53 & 48.9 & 4.28 & 7.98 & 93.9 & $\mathrm{HR}$ \\
\hline $\mathrm{BC} 2 \mathrm{~F} 2-12$ & 114.71 & 15.32 & 18 & 77 & 108 & 15 & 33.56 & 179 & 78.83 & 48.06 & 3.96 & 8.37 & 92.9 & $\mathrm{HR}$ \\
\hline Mean & $113.41^{\mathrm{a}}$ & $13.97^{\mathrm{a}}$ & $16.22^{\mathrm{a}}$ & $77.56^{a}$ & $105.56^{\mathrm{a}}$ & $16.44^{\mathrm{a}}$ & $32.33^{\mathrm{a}}$ & $172.44^{\mathrm{a}}$ & $80.80^{\mathrm{a}}$ & $53.87^{a}$ & $4.22^{\mathrm{a}}$ & $8.81^{\mathrm{a}}$ & 95.32 & \\
\hline SE & \pm 1.06 & \pm 0.55 & \pm 0.81 & \pm 0.34 & \pm 0.71 & \pm 0.87 & \pm 0.64 & \pm 3.98 & \pm 0.69 & \pm 1.82 & \pm 0.13 & \pm 0.25 & & \\
\hline $\begin{array}{l}\text { Recurrent } \\
\text { Parent }\end{array}$ & $115.6^{\mathrm{b}}$ & $12.16^{\mathrm{b}}$ & $15.2^{\mathrm{b}}$ & $83.11^{b}$ & $119.67^{b}$ & $14^{\mathrm{b}}$ & $30.3^{b}$ & $150^{b}$ & $75.61^{b}$ & $48.63^{b}$ & $3.11^{\mathrm{b}}$ & $8.02^{b}$ & & \\
\hline SE & \pm 1.39 & \pm 0.98 & \pm 0.55 & \pm 1.54 & \pm 0.85 & \pm 0.53 & \pm 1.01 & \pm 3.51 & \pm 0.69 & \pm 1.77 & \pm 0.12 & \pm 0.27 & & \\
\hline
\end{tabular}

Note: $\mathrm{PH}=$ plant height, $\mathrm{FLWR}=$ flag-leaf length: width ratio, $\mathrm{NP} / \mathrm{H}=$ number of panicles per hill, $\mathrm{DF}=$ days to $50 \%$ flowering, $\mathrm{DM}=$ days to maturity, $\mathrm{NT}=$ number of effective tillers, $\mathrm{PL}=$ panicle length, TNG/P = total number of grains per panicle, $1000 \mathrm{GW}=$ one thousand grain weight, TGW/H $=$ total grain weight per hill, $\mathrm{SLWR}=$ seed length: width ratio, $\mathrm{Y} / \mathrm{HA}=$ yield per hectare, $\% \mathrm{RPGR}=$ percentage recurrent parent genome recovery, $\mathrm{P}=$ pathotype. $(\mathrm{a}, \mathrm{b})$ : Values that follow the same alphabets are statistically the same $(p>0.05)$ while values that follow different alphabets are statistically different $(p<0.05)$ from each other. 


\section{Discussion}

2 The result presented above could ascertain the marker-assisted background choice's usefulness in acquiring recurrent

3 parent genome recovery data. Also, the background screening reveals information about the donor and heterozygous

4 genome segments. The selection of progenies with the highest recurrent parent genome recovery was the aim of the

5 crop breeder. As a result, progenies got the target genes without having to give up their recurrent parent genes. A

6 minor ratio of recurrent parent genome recovery was recorded in some $\mathrm{BC} 1 \mathrm{~F} 1$ and $\mathrm{BC} 2 \mathrm{~F} 2$ progenies when both stages

7 of backcrossing were compared to the theoretical mean. These outcomes are in line with (Neeraja et al., 2007; Yi,

8 Nwe, Vanavichit, Chai-arree, \& Toojinda, 2009). Besides, the author in (Sundaram et al., 2008) labeled a "pull" over

9 an indefinite technique that might be used by the gene of attention in a study to favor the transit of further loci from

10 the donor gene, resulting in a lower proportion of recurrent parent genome recovery than the hypothetical mean.

11 Nevertheless, the generality of the individuals at both BC1F1 and BC2F2 reached the MABB hypothetical recurrent

12 parent genome recovery of $81 \%$ and $92 \%$, respectively, at both backcross generations (Hasan et al., 2015; Matthew,

13 2012). The current study results agree with the results of researchers in (Martínez et al., 1998; Sabu, Abdullah, Lim,

$14 \&$ Wickneswari, 2006). They discovered that grain yields do not differ significantly between progenies and their 15 parents.

The number of panicles obtained in rice is determined by the number of productive tillers (Hossain, Islam, \& Hasanuzzaman, 2008). In this study, a considerable rise in panicle length and the total number of grains per panicle was observed. These have all contributed to the strengthened lines' grain yield recovery. The high grain yield in rice has been associated with the number of tillers that produce grain and grains per panicle (Dutta, Mia, \& Khanam, 2002; Kusutani, Tovata, Asanuma, \& Cui, 2000). In the same way, the grain's length and width are crucial quantitative characters that closely correlate with external physical quality (Sarif et al., 2020; Chunhai Shi, Zhu, Wu, \& Fan, 2000). It has been observed that the shape of the grain/seed is determined by the length and width of the grain (Huang, Wang, Yamaji, \& Ma, 2020; Juliano, 1993). However, Shi and Zhu reported that the grain shape has been (CH Shi \& Zhu, 1996) to be simultaneously affected by endosperm, triploid, maternal, and cytoplasmic genes. It was observed that $18.6 \%$ (BC1F1-521) was the maximum percentage of heterozygous genome segment gained in BC1F1 with a recurrent parent genome recovery of $77.9 \%$. A slight background marker variation of 1.1\% from the hypothetical $79 \%$ predictable from MABB was observed in the result.

This showed a deviation of some of the markers from the heterozygous genome segment. It is stated by the researcher (Lau et al., 2017) that the increased heterozygous segment in some progenies may be due to the favored inheritance of IRBB60 alleles at some loci. This result has become normal because about five progenies out of the seven BC1F1 screened individuals had more than the mean $(10.84 \%)$ ratio in the heterozygous genome segment. Nevertheless, a decrease in the $\mathrm{BC} 2 \mathrm{~F} 1$ generation, because $7.3 \%$, was recorded as the maximum ratio of heterozygous genome segment whereas all $\mathrm{BC} 2 \mathrm{~F} 1$ individuals met the predictable $\mathrm{MABB}$ recurrent parent genome recovery of $92.2 \%$. These results align with the researcher in (Miah et al., 2015), who stated 75.40-91.3\% in BC1F1 and 80.40-96.7\% in BC2F2 generations as the extent of recurrent parent genome recovery. 
In their parts, the author in (Kim et al., 2014) detected that the role could determine the transmission pattern of alleles functioned by F1 may be either a male or a female parent. They discovered conveyance proportion deformation at some loci at BC1F1 individuals gained from the F1 cross that implicated indica $\mathrm{x}$ japonica with mutual crosses. For instance, when F1 represents the female parent's role, japonica alleles were preferably separated through F1 meiosis at several loci, whereas fertilization between the japonica embryo sac and indica pollen was greatly possible when backcrossed to indica. As a result of this, the marker separation inclined to the heterozygous genome segment. In the present research, the female plants were presented by F1 and BC1F1 selected progenies, whereas MR297 served as the males that donated pollens. A transmission ratio distortion that might have occurred during meiosis was indicated by the great heterozygous genome segment detected in several BC1F1 individuals. During meiosis at F1 and BC1F1, the IRBB60 allele was mostly preferred because there were more probabilities of pollination between the embryo sac that approved the IRBB60 allele and MR297 pollen. At the same time, the researcher in (Koide et al., 2008) labeled transportation proportion deformation as the superior spread of alleles.

When a couple of alleles are preferentially recovered in a heterozygote individual, such occurrence causes a variation in the regularity of genotypes predictable from the Mendelian proportion. Frequently, the noticed separation deformation occurs in varied crosses like the indica $\mathrm{x}$ japonica inter-sub specific cross and Basmati $\mathrm{x}$ indica intergroup cross (Shanmugavadivel et al., 2013). Presently, the technique implicated in the conveyance proportion deformation of numerous loci or genes in varied rice crosses has been found and utilized broadly by breeders. These contain sterility gene (S) (Chen et al., 2008), gametophyte gene (ga) (Wu et al., 2010) and hybrid breakdown genes (hbd) (Yamamoto et al., 2007). Although some backcross progenies in this breeding program were harmed by the impacts of genes implicated in transition proportion deformation, which preferred IRBB60 alleles in backcrossing with MR297, few backcross individuals had a great ratio heterozygous genome segments, particularly in BC2F1. Increasing the recurrent parent genome recovery and reducing the heterozygous and donor genome segment to a fundamental grade was the essence of background selection. The BC1F1 and $\mathrm{BC} 2 \mathrm{~F} 1$ backcross generations might be considered most efficient, with the mean of the recurrent parent genome recovery increasing from 80.11 percent at $\mathrm{BC} 1 \mathrm{~F} 1$ to 95.3 percent at $\mathrm{BC} 2 \mathrm{~F} 1$. The $\mathrm{BC} 2 \mathrm{~F} 2$ seeds to be planted in the next season will be produced from nominated individuals from the $\mathrm{BC} 2 \mathrm{~F} 1$ progenies that were selfed to produce. This was possible because self-fertilization can increase non-carrier chromosomes' homozygosity, decrease heterozygosity, and avert more separation after trials (Hasan et al., 2015; Okporie, Chukwu, \& Onyishi, 2013; Rajpurohit et al., 2011).

\section{Conclusions}

This study demonstrated that marker-assisted backcross breeding can be used to introduce resistance genes from the donor parent into the recipient parent. It also demonstrated the value of foreground selection in discovering bacterial leaf blight resistance target genes. This research also demonstrated the ability of background selection to recover the recurrent parent genome. This breeding effort also shown the capacity of the backcross breeding approach to introduce resistance genes and diminish the donor parent genome; this is the success story. 


\section{References}

Ashkani, S., Rafii, M. Y., Rusli, I., Sariah, M., Abdullah, S. N. A., Rahim, H. A., \& Latif, M. (2012). SSRs for markerassisted selection for blast resistance in rice (Oryza sativa L.). Plant Molecular Biology Reporter, 30(1), 7986.

Chen, J., Ding, J., Ouyang, Y., Du, H., Yang, J., Cheng, K., . . Yao, J. (2008). A triallelic system of S5 is a major regulator of the reproductive barrier and compatibility of indica-japonica hybrids in rice. Proceedings of the National Academy of Sciences, 105(32), 11436-11441.

Collard, B. C., \& Mackill, D. J. (2008). Marker-assisted selection: an approach for precision plant breeding in the twenty-first century. Philosophical Transactions of the Royal Society B: Biological Sciences, 363(1491), 557-572.

Das, G., Rao, G. J., Varier, M., Prakash, A., \& Prasad, D. (2018). Improved Tapaswini having four BB resistance genes pyramided with six genes/QTLs, resistance/tolerance to biotic and abiotic stresses in rice. Scientific reports, 8(1), 1-16.

Doyle, J. J. (1990). Isolation of plant DNA from fresh tissue. Focus, 12, 13-15.

Dutta, R., Mia, M. B., \& Khanam, S. (2002). Plant architecture and growth characteristics of fine grain and aromatic rices and their relation with grain yield. International Rice Commission Newsletter, 51, 51-55.

Hasan, M. M., Rafii, M. Y., Ismail, M. R., Mahmood, M., Rahim, H. A., Alam, M. A., , . Latif, M. A. (2015). Markerassisted backcrossing: a useful method for rice improvement. Biotechnology \& Biotechnological Equipment, 29(2), 237-254.

Hospital, F. (2001). Size of donor chromosome segments around introgressed loci and reduction of linkage drag in marker-assisted backcross programs. Genetics, 158(3), 1363-1379.

Hossain, M., Islam, M., \& Hasanuzzaman, M. (2008). Influence of different nitrogen levels on the performance of four aromatic rice varieties. Int. J. Agri. Biol, 10(6), 693-696.

Huang, S., Wang, P., Yamaji, N., \& Ma, J. F. (2020). Plant nutrition for human nutrition: hints from rice research and future perspectives. Molecular Plant, 13(6), 825-835.

Jasim Aljumaili, S., Rafii, M., Latif, M., Sakimin, S. Z., Arolu, I. W., \& Miah, G. (2018). Genetic diversity of aromatic rice germplasm revealed by SSR markers. BioMed research international, 2018.

Juliano, B. O. (1993). Rice in human nutrition: Int. Rice Res. Inst.

Kim, B., Jang, S. M., Chu, S.-H., Bordiya, Y., Akter, M. B., Lee, J., . . Koh, H.-J. (2014). Analysis of segregation distortion and its relationship to hybrid barriers in rice. Rice, 7(1), 3.

Koide, Y., Onishi, K., Nishimoto, D., Baruah, A. R., Kanazawa, A., \& Sano, Y. (2008). Sex-independent transmission ratio distortion system responsible for reproductive barriers between Asian and African rice species. New Phytologist, 179(3), 888-900.

Kusutani, A., Tovata, M., Asanuma, K., \& Cui, J. (2000). Studies on the varietal differences of harvest index and morphological characteristics of rice. Japanese J. Crop Sci, 69, 359-364.

Lau, W. C. P., Rafii, M. Y., Ismail, M. R., Puteh, A., Latif, M. A., Asfaliza, R., \& Miah, G. (2017). Development of advanced fragrant rice lines from MR269× Basmati 370 through marker-assisted backcrossing. Euphytica, 213(1), 1-15.

Mackill, D. (2006). From genes to farmere s fields. Rice Today, 5, 28-31.

Martínez, C., Tohme, J., López, J., Borrero, J., McCouch, S., \& Almeida, A. (1998). Identification and utilization of genes from wild rice germplasm for the improvement of yield and stress resistance. Proceedings of 27th Rice Technical Working Group (1-4 March 1998, Reno, Nevada, USA).

Matthew, R. (2012). Backcrossing, Backcross (BC) population and backcross breeding. Plant Breeding and Genomics. The Ohio State University, 1. 
Miah, G., Rafii, M. Y., Ismail, M. R., Puteh, A. B., Rahim, H. A., \& Latif, M. A. (2015). Recurrent parent genome recovery analysis in a marker-assisted backcrossing program of rice (Oryza sativa L.). Comptes rendus biologies, 338(2), 83-94.

Neeraja, C. N., Maghirang-Rodriguez, R., Pamplona, A., Heuer, S., Collard, B. C., Septiningsih, E. M., .. . Ismail, A. M. (2007). A marker-assisted backcross approach for developing submergence-tolerant rice cultivars. Theoretical and Applied Genetics, 115(6), 767-776.

Okporie, E., Chukwu, S., \& Onyishi, G. (2013). Phenotypic recurrent selection for increase yield and chemical constituents of maize (Zea mays L.). World Applied Sciences Journal, 21(7), 994-999.

Olalekan, K. K., Rafii, M. Y., Salleh, A. M., Mohamed, M. T., Ahmad, K., Misran, A., . . Samuel, C. (2019). Analysis of recurrent parent genome recovery in marker-assisted backcross breeding programme in Watermelon. Int J Sci Technol Res, 8(08), 945-955.

Rajpurohit, D., Kumar, R., Kumar, M., Paul, P., Awasthi, A., Basha, P. O., . . Dhaliwal, H. S. (2011). Pyramiding of two bacterial blight resistance and a semidwarfing gene in Type 3 Basmati using marker-assisted selection. Euphytica, 178(1), 111-126.

Rice, I. N. f. G. E. o. (1996). Standard evaluation system for rice: IRRI, International Rice Research Institute.

Sabu, K. K., Abdullah, M. Z., Lim, L. S., \& Wickneswari, R. (2006). Development and evaluation of advanced backcross families of rice for agronomically important traits. Commun. Biometry Crop Sci, 1(2), 111-123.

Sarif, H. M., Rafii, M. Y., Ramli, A., Oladosu, Y., Musa, H. M., Rahim, H. A., . . Chukwu, S. C. (2020). Genetic diversity and variability among pigmented rice germplasm using molecular marker and morphological traits. Biotechnology \& Biotechnological Equipment, 34(1), 747-762.

Shanmugavadivel, P., Mithra, S. A., Dokku, P., Kumar, K. A. R., Rao, G., Singh, V., . . Mohapatra, T. (2013). Mapping quantitative trait loci (QTL) for grain size in rice using a RIL population from Basmatix indica cross showing high segregation distortion. Euphytica, 194(3), 401-416.

Shi, C., \& Zhu, J. (1996). Genetic analysis of endosperm, cytoplasmic and maternal effects for exterior quality traits in indica rice. Journal of Biomathematics, 11(1), 73-81.

Shi, C., Zhu, J., Wu, J., \& Fan, L. (2000). Genetic and genotypex environment interaction effects from embryo, endosperm, cytoplasm and maternal plant for rice grain shape traits of indica rice. Field Crops Research, 68(3), 191-198.

Singh, A., Sarma, B., Singh, P., \& Nandan, R. (2013). Screening of rice (Oryza sativa L.) germplasms against Xanthomonas oryzae pv. oryzae. Journal of Eco-friendly Agriculture, 8(1), 86-88.

Sundaram, R. M., Vishnupriya, M. R., Biradar, S. K., Laha, G. S., Reddy, G. A., Rani, N. S., . . Sonti, R. V. (2008). Marker assisted introgression of bacterial blight resistance in Samba Mahsuri, an elite indica rice variety. Euphytica, 160(3), 411-422.

Wu, Y. P., Ko, P. Y., Lee, W. C., Wei, F. J., Kuo, S. C., Ho, S. W., . . Lin, Y. R. (2010). Comparative analyses of linkage maps and segregation distortion of two F2 populations derived from japonica crossed with indica rice. Hereditas, 147(5), 225-236.

Yamamoto, T., Kimura, T., Terakami, S., Nishitani, C., Sawamura, Y., Saito, T., . . Hayashi, T. (2007). Integrated reference genetic linkage maps of pear based on SSR and AFLP markers. Breeding Science, 57(4), 321-329.

Yi, M., Nwe, K. T., Vanavichit, A., Chai-arree, W., \& Toojinda, T. (2009). Marker assisted backcross breeding to improve cooking quality traits in Myanmar rice cultivar Manawthukha. Field Crops Research, 113(2), 178186.

Yugander, A., Sundaram, R. M., Singh, K., Ladhalakshmi, D., Subba Rao, L. V., Madhav, M. S., . . Laha, G. S. (2018). Incorporation of the novel bacterial blight resistance gene Xa38 into the genetic background of elite rice variety Improved Samba Mahsuri. PloS one, 13(5), e0198260.

Zuki, Z. M., Rafii, M. Y., Ramli, A., Oladosu, Y., Latif, M. A., Sijam, K., . . Sarif, H. M. (2020). Segregation analysis for bacterial leaf blight disease resistance genes in rice 'MR219'using SSR marker. Chilean journal of agricultural research, 80(2), 227-233. 